\title{
Sexy thoughts: Effects of sexual cognitions on testosterone, cortisol, and arousal in women
}

\author{
Katherine L. Goldey ${ }^{a}$, Sari M. van Anders ${ }^{\text {b,* }}$ \\ a Department of Psychology, University of Michigan, 530 Church Street, Ann Arbor, MI 48109, USA \\ ${ }^{\mathrm{b}}$ Departments of Psychology E Women's Studies, Program in Neuroscience, Reproductive Sciences Program, University of Michigan, 530 Church Street, Ann Arbor, MI 48109, USA
}

\section{A R T I C L E I N F O}

Article history:

Received 17 June 2010

Revised 2 December 2010

Accepted 15 December 2010

Available online $\mathrm{xxxx}$

\section{Keywords:}

Ceiling effect

Cognition

Cortisol

Hormonal contraceptives

Hormone

Sexual arousal

Sexual experience

Sexual thoughts

Testosterone

Women

\begin{abstract}
A B S T R A C T
Previous research suggests that sexual stimuli increase testosterone $(\mathrm{T})$ in women and shows inconsistent effects of sexual arousal on cortisol (C), but effects of cognitive aspects of arousal, rather than behaviors or sensory stimuli, are unclear. The present study examined whether sexual thoughts affect $\mathrm{T}$ or $\mathrm{C}$ and whether hormonal contraceptive (HC) use moderated this effect, given mixed findings of $\mathrm{HC}$ use confounding hormone responses. Participants (79 women) provided a baseline saliva sample for radioimmunoassay. We created the Imagined Social Situation Exercise (ISSE) to test effects of imagining social interactions on hormones, and participants were assigned to the experimental (sexual) or one of three control (positive, neutral, stressful) conditions. Participants provided a second saliva sample $15 \mathrm{~min}$ post-activity. Results indicated that for women not using HCs, the sexual condition increased T compared to the stressful or positive conditions. In contrast, $\mathrm{HC}$ using women in the sexual condition had decreased $\mathrm{T}$ relative to the stressful condition and similar $\mathrm{T}$ to the positive condition. The effect was specific to $\mathrm{T}$, as sexual thoughts did not change C. For participants in the sexual condition, higher baseline T predicted larger increases in sexual arousal but smaller increases in T, likely due to ceiling effects on $\mathrm{T}$. Our results suggest that sexual thoughts change $\mathrm{T}$ but not $\mathrm{C}$, baseline $\mathrm{T}$ levels and $\mathrm{HC}$ use may contribute to variation in the T response to sexual thoughts, and cognitive aspects of sexual arousal affect physiology.
\end{abstract}

(c) 2010 Elsevier Inc. All rights reserved.
A variety of evidence links testosterone $(\mathrm{T})$ and sexuality-related contexts, including sexual desire, arousal, stimuli, and behavior (for reviews, see Bancroft, 2005; Regan, 1999; van Anders and Watson, 2006c). For example, partnered sexual activity increases $T$ in women (van Anders et al., 2007) and men (Dabbs and Mohammed, 1992). However, physical partner presence may not always be necessary for a sexually-stimulated $\mathrm{T}$ response, as exposure to visual sexual stimuli elevates T in men (Hellhammer et al., 1985; Redoute et al., 2000; Rowland et al., 1987; Stoleru et al., 1999). Findings on T responses to sexual stimuli other than partnered activity in women are mixed. One study reported small increases in T after women viewed an erotic film and masturbated to orgasm (Exton et al., 1999). However, van Anders et al. (2009) found no statistical change in $T$ in response to an erotic film when masturbation was not involved, which might imply that orgasm or sexual activity is required for the $\mathrm{T}$ response to occur in women. Interestingly though, another study found that women's $\mathrm{T}$ increased after watching a film depicting an attractive man initiating a romantic relationship with a woman and imagining themselves as the woman in the film (Lopez et al., 2009). Thus, neither sexual behavior

\footnotetext{
* Corresponding author. Fax: +1 7347637480 .

E-mail addresses: kalusi@umich.edu (K.L. Goldey), smva@umich.edu (S.M. van Anders).
}

nor partner presence may be required to induce a $\mathrm{T}$ response, but sexual arousal or interest might be.

If sexual behavior increases $\mathrm{T}$, is it the behavior, or other sexual elements, that affect physiology? Human sexual behavior and arousal include several cognitive elements acknowledged as important to the sexual response, including perceptions of genital and autonomic arousal (Toledano and Pfaus, 2006), a psychological readiness to respond to sexual stimuli (Toledano and Pfaus, 2006), and recognition of a situation "as sexual" (Rosen and Beck, 1988; Stoleru et al., 1999). Here, we focus on cognitive arousal as a "state" encompassing the factors described above (perceptions of genital and autonomic arousal, etc.) which occurs in response to a stimulus, and this stimulus could be sensory or imagined. In addition to their role in sexual arousal, sexual cognitions may induce $\mathrm{T}$ responses, given that van Anders et al. (2007) found that women's T was higher before intercourse than before control activities (cuddling or exercise), suggesting that anticipation of sexual activity may increase $T$. In women in long-distance relationships, $\mathrm{T}$ increases the day before women first see their partners after a separation, which may also reflect anticipation of sexual activity (Hamilton and Meston, 2010). One previous study found preliminary evidence that discussing topics of a sexual nature during an interview resulted in increased concentrations of luteinizing hormone (which cues $\mathrm{T}$ release) in men (LaFerla et al., 1978). And, Anonymous (1970) reported that a 
biomarker of $\mathrm{T}$ (beard growth) appeared to increase in anticipation of sexual activity. Despite these suggestive findings, no studies have explored whether simply thinking about sex, without the presence of partners, sexual behavior, or external sensory stimuli, can change $T$.

Though there is no clear consensus at present with $\mathrm{T}$, the role of cortisol (C) in sexuality is even less clear. C levels appear to decrease in women after viewing an erotic video (Hamilton et al., 2008; van Anders et al., 2009), though two studies found no difference in $C$ responses between women in erotic video and control video conditions (Exton et al., 2000; Heiman et al., 1991). Masturbation to orgasm does not appear to affect C in women (Exton et al., 1999). Finally, in women experiencing passionate love, $\mathrm{C}$ increased in response to thinking and writing about a romantic partner compared to thinking and writing about a friend (Loving et al., 2009). Although this finding suggests that activities involving mental imagery and cognitions about relational intimacy can elicit $C$ responses, previous research has not examined whether thinking and writing about sexuality could produce a similar response.

Hormonal responses to sexual stimuli may vary as a result of baseline hormone levels, which is why most studies have used withinparticipant designs. However, large numbers of young women are using hormonal contraceptives (HCs), so HC use may lead to a large source of between-participant variability. HC use decreases baseline levels of free T (Bancroft et al., 1991; Coenen et al., 1996; Edwards and O'Neal, 2009; Greco et al., 2007; Swinkels et al., 1988; Thorneycroft et al., 1999; van Anders and Watson, 2006a) and increases concentrations of sex-hormone binding globulin (SHBG), a protein that binds T, resulting in the lower free T (Murphy et al., 1990; Swinkels et al., 1988; Thorneycroft et al., 1999). However, whether HC use affects T changes in response to social stimuli is less clear. Although some studies have not found effects of HC status on T responses to social stimuli (Edwards and O'Neal, 2009; van Anders et al., 2007), previous authors have emphasized the need to clarify how HC use is associated with between-participant variability in T responses (Edwards and O'Neal, 2009; Josephs, 2009). Furthermore, recent evidence suggests that HC use attenuates women's $\mathrm{T}$ responses to stimuli involving an attractive man (Lopez et al., 2009).

HC use affects baseline T levels, so there is reason to suspect effects on responses. There is also evidence that $\mathrm{HC}$ use affects $\mathrm{C}$ responses to stress, but perhaps not to sexuality. Although women using HCs show similar $C$ responses to stress compared with women in the follicular phase, they show blunted $C$ responses to stress compared with women in the luteal phase (Kirschbaum et al., 1999). However, Hamilton et al. (2008) found no effect of HC use on baseline $\mathrm{C}$ or $\mathrm{C}$ responses to sexual stimuli; likewise, $\mathrm{HC}$ use did not affect $\mathrm{C}$ responses to thinking about a romantic partner (Loving et al., 2009) or to cues involving an attractive man (Lopez et al., 2009). As such, effects of HC use on C responses, like $\mathrm{T}$ responses, to sexual stimuli are still unclear.

In addition to baseline levels of hormones, sexual experience may moderate physiological responses to sexual stimuli. For example, sexually experienced male rats show higher $\mathrm{T}$ responses to mating than naïve males (Kamel et al., 1975). Sexual experience is required for male rats to show a $\mathrm{T}$ response when exposed to a receptive female, and experience increases the $C$ response to mating (Bonilla-Jaime et al., 2006). For male rats, past mating experiences may prompt the formation of learned associations between cues relevant to mating and mating itself, resulting in $\mathrm{T}$ responses to cues (e.g., visual, olfactory) associated with mating (Alexander et al., 1994; Graham and Desjardins, 1980). In humans, Roney et al. (2003) (c.f. Roney et al., 2007; van der Meij et al., 2008) found that men with recent sexual experience showed an increase in $\mathrm{T}$ after a social interaction with a woman, whereas men with no recent experience did not. Past research has not addressed the role of previous experience on women's hormonal responses to sexual stimuli.

In the current study, we investigated whether sexually arousing thoughts in the absence of sensory stimuli result in a $\mathrm{T}$ or $\mathrm{C}$ response in women. Because no established experimental paradigm exists to assess the effects of sexual cognitions on physiology, we developed a novel design, the Imagined Social Situation Exercise (ISSE), to determine whether sexual cognitions affect $\mathrm{T}$ and $\mathrm{C}$. We compared hormone responses to imagining and describing a sexually arousing situation to three control scenarios: a) a neutral condition to control for passage of time and imagining a social interaction; b) a stressful condition to control for autonomic arousal and the potentially stressful response to imagining a sexual encounter; and c) a positive condition to control for feelings of pleasure, reward, and affiliation that might accompany imagining a sexual encounter. In each condition, participants read about and imagined themselves in a social situation and responded to openended questions about the situation. Considering that imagining oneself as a participant in a situation (Janssen et al., 2003) and focusing on responses as well as stimuli (Dekker and Everaerd, 1988) facilitate sexual arousal, our paradigm was designed to elicit meaningful sexual arousal as the open-ended questions targeted both participants' actions and feelings in their imagined scenario.

Based on evidence that sexual arousal increases $\mathrm{T}$ in women (Dabbs and Mohammed, 1992; Exton et al., 1999; van Anders et al., 2007), we hypothesized that participants in the sexual condition would show an increase in T compared to participants in the control conditions. We examined the effect of sexual thoughts on C, but given previous conflicting findings on $\mathrm{C}$ responses to sexual stimuli (Exton et al., 1999, 2000; Hamilton et al., 2008; van Anders et al., 2009), we did not make a specific prediction for changes in $C$ in response to sexual thoughts. Finally, we explored whether baseline levels of hormones, HC use, or sexual experience influenced $\mathrm{T}$ or $\mathrm{C}$ responses to sexual thoughts. Effects of sexual thoughts on hormones have potentially broad implications for understanding the link between hormones and sexuality, and, even more broadly, the effects of cognitions on physiology.

\section{Method}

\section{Participants}

Participants were 79 women (mean age $=20.58$ years, SD $=$ 4.18 years, range $=18-39$ yrs) recruited from the undergraduate psychology pool and the community through online advertisements and posters. Participants were compensated with course credit or $\$ 15$. The majority of participants ( $n=73$ ) were students, but some $(n=21)$ were employed in a variety of occupations. All participants had graduated high school and had some college, and several $(n=8)$ had graduated from college. Participants self-identified their race/ethnicity, and we categorized their responses such that we had 6 African American, 15 Asian, $7 \mathrm{Bi} /$ multiracial, 2 Hispanic, and 49 White/Caucasian participants. Most participants had spent the majority of their lives in the USA, although eight participants had lived in the USA for 10 years or less. Participants self-identified their sexual orientation; the majority identified as heterosexual $(n=69)$, three participants identified as bisexual, one as heterosexual/bicurious, and one as queer, with five nonresponders. Participants were varied by relationship status: 21 were single, 22 were casually partnered, and 35 were in committed partnerships, with one nonresponder. With the exception of hormonal contraceptive users, participants $(n=13)$ who were using medications that affect hormones (e.g., medications containing corticosteroids), using medications with sexual side effects (e.g., antidepressants), and/or had a medical condition that may affect hormones (e.g., ovarian cysts) were excluded from subsequent analyses.

\section{Materials and methods}

\section{Health and background questionnaire}

This questionnaire contained demographic items to describe the sample, height and weight to calculate BMI (body mass index, a measure of weight adjusted for height), and items regarding possible confounds with hormone measures. 
Affect and Arousal Scale (Heiman and Rowland, 1983)

This measure was designed to assess state affect and arousal in studies of subjective and genital sexual arousal. We used it to assess affect and arousal before and after the ISSE, and we modified the scale by adding four items relevant to the positive or stressful conditions: sad, happy, stressed, and relaxed. Our modified version included 32 items that made up five subscales: subjective sexual arousal (e.g., "sexually aroused"), autonomic arousal (e.g., "faster breathing than normal"), anxiety (e.g., "worried"), positive affect (e.g., "happy"), and negative affect (e.g., "embarrassed"). We did not include the items from one subscale - perception of genital sexual arousal - to avoid excessively priming participants to feel sexually aroused, and we omitted the item "feminine" as it was irrelevant to our measures of interest. Participants rated how well each word described their current feelings on a 7-point Likert scale from "1" = "Not at all" to "7" = "Intensely."

\section{Imagined Social Situation Exercise (ISSE)}

Participants were randomly assigned to the sexual condition or one of three control conditions: neutral, stressful, or positive. In each of the four conditions (described further below), participants read about and imagined themselves in a social situation and responded to open-ended questions about the situation. The prompts and questions were phrased in a parallel manner across conditions (see Appendix for the texts of the prompts and open-ended questions for each condition). The openended questions allowed us to target specific aspects of the imagined interaction across all participants and to control for the level of detail participants used while imagining. We did not control the amount of time participants spent imagining and responding to the questions, but we suggested an average response amount of 2-3 sentences for each question in order to standardize the amount of time spent as best as possible. Participants typed their responses in an online questionnaire, and the program recorded the amount of time they spent responding. Across conditions, participants spent an average of $8.31 \mathrm{~min}$ on the questions $(S D=5.06 \mathrm{~min})$. There were no significant differences between conditions in the amount of time spent on the open-ended questions, $F(3,62)=2.16, p=0.102$, or in the total number of words used in response to the open-ended questions, $F(3,62)=1.46, p=0.234$.

The four conditions were:

Sexual. Participants imagined a positive sexual encounter with an attractive person. We intentionally did not specify characteristics of the sexual partner and sexual activity in the prompt to allow participants to self-define the type of person and situation attractive to them. Participants were simply instructed to imagine that they found their sexual partner very attractive and enjoyed the sexual activity very much.

Neutral. To control for the passage of time and the response to imagining a social interaction, participants imagined an ordinary interaction with a postal worker while mailing a package at the post office.

Stressful. We included the stressful condition in order to control for effects on $\mathrm{T}$ or $\mathrm{C}$ caused by autonomic arousal or the potentially stressful response to imagining a sexual situation. The prompt described a job interview with a cold and skeptical interviewer. The interview scenario was chosen for the stressful condition based on the frequent use of job interview-like tasks (e.g., the Trier Social Stress Test: Kirschbaum et al., 1993) to elicit physiological stress responses in laboratory settings.

Positive. To control for positive arousal (i.e., reward, pleasure, affiliation) caused by imagining a sexual situation, participants imagined celebrating a desired job offer with a friend.

\section{Relationships and sexuality questionnaire}

This questionnaire contained items about relationships and sexuality including relationship status, frequency of masturbation, and frequency of partnered sexual activity. Participants were asked about number of lifetime sexual partners (Likert-type scale from "0" = "0 partners" to " $5 "=$ " $21+$ partners") and if they reported ever having been sexually active, they were asked to indicate the length of time since most recent sexual activity (Likert scale from "1" = "Today" to "7" = "Over a year ago"). These questions were asked separately for sexual activity including passionate kissing or touching and for sexual activity defined as contact involving the participant's or another person's genitals. Participants who indicated that they had never been sexually active with a partner were coded as " 8 " = "Never" for length of time since sexual activity.

\section{Saliva samples}

We measured hormones using saliva sampling, which is newer than blood sampling but provides several advantages. Saliva collection is less of a biohazard, less invasive, and less likely to trigger any sort of stress response associated with blood draws. Arguably, saliva sampling is less likely to interfere with sexual arousal than blood sampling. Saliva is frequently used in behavioral research, and salivary assays are well established and validated. For example, salivary T correlates well with free serum T (Khan-Dawood et al., 1984; Magrini et al., 1986; Swinkels et al., 1988) and total serum T (Granger et al., 2004; Shirtcliff et al., 2002). However, some inconsistent results suggest that salivary $\mathrm{T}$ measurements may underestimate the strength of T-behavior associations in women, so larger samples of women should be used in order to remedy this problem (Granger et al., 2004; Shirtcliff et al., 2002). Salivary C also correlates well with serum C (e.g., Lippi et al., 2009; Lo et al., 1992). Salivary steroid levels reflect the "bioavailable" fraction of hormone that is unbound or weakly bound to albumin and that can bind with receptors (Quissell, 1993).

Participants provided two unstimulated saliva samples by spitting into $17 \mathrm{~mL}$ polystyrene tubes after rinsing their mouths with water; samples were frozen until assay. $\mathrm{T}$ and $\mathrm{C}$ were assayed by radioimmunoassay at the Core Assay Facility, University of Michigan, using commercially available kits from Siemens. For T, we used the protocol described by Campbell et al. (1999), which has been successfully used in previous studies to measure T in women (e.g., Schultheiss et al., 2004). T was run in one batch, and the intra-assay coefficient of variation was $12.83 \%$ for low hormone and $3.16 \%$ for high hormone. Analytical sensitivity $\left(B_{0}-2 \mathrm{SD}\right)$ for $\mathrm{T}$ was $1.14 \mathrm{pg} / \mathrm{mL}$. For $\mathrm{C}$, we followed the method described by Wirth et al. (2006). The intra-assay coefficient of variation was $7.84 \%$ for low hormone and $2.86 \%$ for high hormone, and the inter-assay coefficient of variation was $9.22 \%$ for low hormone and $3.69 \%$ for high hormone. Analytical sensitivity $\left(B_{0}-2 \mathrm{SD}\right)$ for $C$ was $0.09 \mathrm{ng} / \mathrm{mL}$. Samples were assayed in duplicate, and the average of duplicates was taken.

\section{Procedure}

All procedures were approved by the University's institutional review board (IRB) and were in compliance with national legislation and the Code of Ethical Principles for Medical Research Involving Human Subjects of the World Medical Association. To avoid the high and rapidly declining steroid levels associated with waking and/or the morning (Axelsson et al., 2005; Khan-Dawood et al., 1984), participants were tested in the afternoon between the hours of 12:00 and 18:00. Participants were tested from October to December in all phases of their menstrual cycles. Although T fluctuates across the cycle, menstrual phase does not need to be controlled for in research involving $T$ unless cycle phase is a variable of interest (Dabbs and de La Rue, 1991; van Anders and Watson, 2006b; van Anders et al., 2007, 2009). Findings on C and menstrual phase are less consistent; one study reported a consistent effect of menstrual phase on salivary $C$ responses to stress (Kirschbaum et al., 1999), but other studies indicate that variation in C across the menstrual cycle is small and variable (Odber et al., 1998) or non-existent (Kudielka and Kirschbaum, 2003; McCormick and Teillon, 2001). Thus, menstrual cycle phase was recorded but not controlled.

Participants were asked to refrain from eating, drinking, smoking, brushing their teeth, or chewing gum for one hour prior to testing. Upon arrival at the laboratory, the participant read and signed an informed 
consent form. An experimenter gave instructions about providing saliva samples and completing the online questionnaire, and the participant was then left alone in a private room with a computer for the remainder of the study. While providing the first saliva sample (i.e., T1, C1), participants completed the health and background questionnaire and the Affect and Arousal Scale. Then, participants completed the ISSE, including the open-ended questions. Immediately following the ISSE, participants completed a second Affect and Arousal Scale and watched a neutral travel film as a time-filler, as evidence indicates delayed effects for social modulation of T (Roney et al., 2007; Schultheiss and Rohde, 2002) and of acute psychological stressors on C (Dickerson and Kemeny, 2004). As the neutral film, participants watched excerpts from one of two randomly assigned travel films for $12.5 \mathrm{~min}$ : Manila: Uptown and Downtown (National Commission on Culture and the Arts, 2003) or Scotland: The Beauty and Majesty (Hinshelwood, 1997) and then provided the second saliva sample (i.e., T2, C2). Thus, approximately 15 min passed between completing the ISSE and providing the second saliva sample. Finally, participants completed the relationships and sexuality questionnaire. This measure was completed after the second saliva sample to avoid any possible stimulating effects of completing this questionnaire on hormones. Participants were reimbursed with credit or $\$ 15$ as relevant.

\section{Results}

\section{Analyses}

We conducted analyses with SPSS 17.0. Because we were interested in changes from baseline to post-activity, we calculated percent change in each hormone (T\%, C\%) by subtracting participants' baseline $\mathrm{T}$ ( or C) from post-activity $\mathrm{T}$ ( or $\mathrm{C}$ ) and dividing this change by baseline $\mathrm{T}$ ( or $\mathrm{C}$ ) and then multiplying by 100 . This provided a measure of the change in $\mathrm{T}$ or $\mathrm{C}$ relative to the baseline level of that particular hormone for each participant. Percent changes are often used to analyze hormone changes from baseline (Carre and Putnam, 2010; Carre et al., 2010; Edwards et al., 2006; Edwards and O'Neal, 2009; van Anders et al., 2007; van Anders et al., 2009), and this measure has been shown to be more sensitive than absolute changes, likely because of the wide betweensubjects variability in baseline hormone levels, and because absolute levels up- and down-regulate receptor density such that relative changes are more meaningful in the face of varying sensitivities. Percent changes in each of the five affect/arousal subscales (subjective sexual arousal, autonomic arousal, anxiety, positive affect, and negative affect) were calculated in a similar manner.

There were several hormone outliers (over 3 SD from the mean as well as visually) who were excluded from analyses that included those variables. There was one outlier for T\%, 4 for $\mathrm{C} 1,2$ for $\mathrm{C} 2$ (one of whom was also an outlier for $\mathrm{C} 1$ ), and 4 for $\mathrm{C} \%$ (one of whom was also the outlier for T\%). Due to low sample quantity, assay results were unavailable for $\mathrm{C} 1$ and $\mathrm{C} 2$ for one participant and $\mathrm{C} 1$ for one additional participant.

Age, time of day, and BMI may be confounded with T and/or C (Axelsson et al., 2005; Burger et al., 2000; Van Cauter et al., 1991, 1996; Wabitsch et al., 1995); however, only BMI was a meaningful covariate for T (BMI, $F[1,45]=7.35, p=0.009$; age, $F[1,45]=1.07, p=0.308$; time, $F[1,45]=1.95, p=0.170)$, and none of the variables were meaningful covariates for C (BMI, $F[1,45]=0.48, p=0.494$; age, $F[1,45]=0.47, p=$ .498 ; time, $F[1,45]=2.07, p=0.157)$. Therefore, only BMI was included as a covariate. Because we were interested in whether T responses differ by HC use (Edwards and O'Neal, 2009; Josephs, 2009; Schultheiss et al., 2003), and T was significantly lower in our data for HC users (T1: $t[64]=$ 3.89, $p<0.001$; T2: $t[64]=3.95, p<0.001$ ), we included HC use as an independent variable in our analyses. We classified participants as either not using HCs (HC- women) or using HCs (HC+ women).

Analyses were conducted using multivariate analyses of covariance (MANCOVAs), and following significant overall effects or trends, post-hoc analyses were conducted using Tukey HSD tests or independent $t$-tests. Correlations were partial correlations controlling for BMI and/or HC use when appropriate.

\section{Manipulation check}

We checked each participant's responses to the open-ended ISSE questions to ensure that the responses matched the condition. The topic of all participants' responses was consistent with their assigned condition; e.g., participants in the sexual condition all described a sexual interaction, and no participants in the other three conditions included sexual content in their responses. For the sexual, stressful, and positive conditions, valence (i.e., positive, negative) matched the condition, but for the neutral condition, responses were less consistent in valence. Therefore, we coded responses in the neutral condition for the presence or absence of neutral, positive, stressful, and/or non-stressful negative content. Of the 15 responses written by participants in the neutral condition, 12 responses included neutral content (e.g., descriptions of the encounter as ordinary or routine), five included positive content (e.g., "[The postal worker] makes your day brighter every time you go in there"), none included stressful content, and six included non-stressful negative content (e.g., "I am annoyed that I have to be at the post office because it is a depressing and dull place to be").

\section{Effects of imagining sexual vs. control situations on affect and arousal}

We conducted a MANOVA to examine whether the imagined situations elicited the expected changes in affect and arousal. Percent changes in each of the five affect/arousal subscales were entered as dependent variables and condition as the independent variable, and there was a significant multivariate effect of condition, $F(15,132)=7.67$, $p<0.001$. There was a significant univariate effect of condition on each of the five subscales: subjective sexual arousal, $F(3,52)=26.25, p<0.001$; autonomic arousal, $F(3,52)=3.48, p=0.022$; anxiety, $F(3,52)=7.36$, $p<0.001$; positive affect, $F(3,52)=15.22, p<0.001$; and negative affect, $F(3,52)=6.76, p=0.001$. First, we checked whether the sexual condition increased subjective sexual arousal significantly more than the other conditions did, and this was supported (all $p$ 's $<0.001$ ). Also, imagining a positive situation elicited significantly higher subjective sexual arousal than imagining a stressful situation, $p=0.047$. The sexual condition also led to significantly larger increases in autonomic arousal compared to the neutral and positive conditions ( $p$ 's $<0.05$ ). Next, we checked whether the stressful condition led to significantly larger increases in anxiety relative to the other conditions, and this was supported (all $p$ 's $<0.02$ ). Negative affect also increased significantly more in the stressful condition relative to all other conditions (all $p$ 's $<0.05$ ). Finally, we checked whether the sexual and positive conditions increased positive affect relative to the other conditions, and this was supported. Positive affect increased significantly in the positive condition compared to the neutral and stressful conditions $(p ' s<0.02)$, and also increased significantly in the sexual condition compared to the stressful condition $(p<0.001)$, with a trend for an increase in the sexual condition compared to the neutral condition $(p=0.078)$. Overall, the four conditions elicited the intended changes in affect and arousal (see Fig. 1).

\section{Hormonal responses to imagined situations}

First, we examined the effects of condition and $\mathrm{HC}$ use on T\% and C\% using a MANCOVA with T\% and C\% as the dependent variables, condition and $\mathrm{HC}$ use as the independent variables, and BMI as the covariate. There was a significant multivariate interaction between condition and $\mathrm{HCs}, F(6,92)=2.57, p=0.024$, which was driven by a significant interaction between condition and HCs for T\%, $F(3,47)=$ $4.92, p=0.005$. There was no significant main effect of condition on 


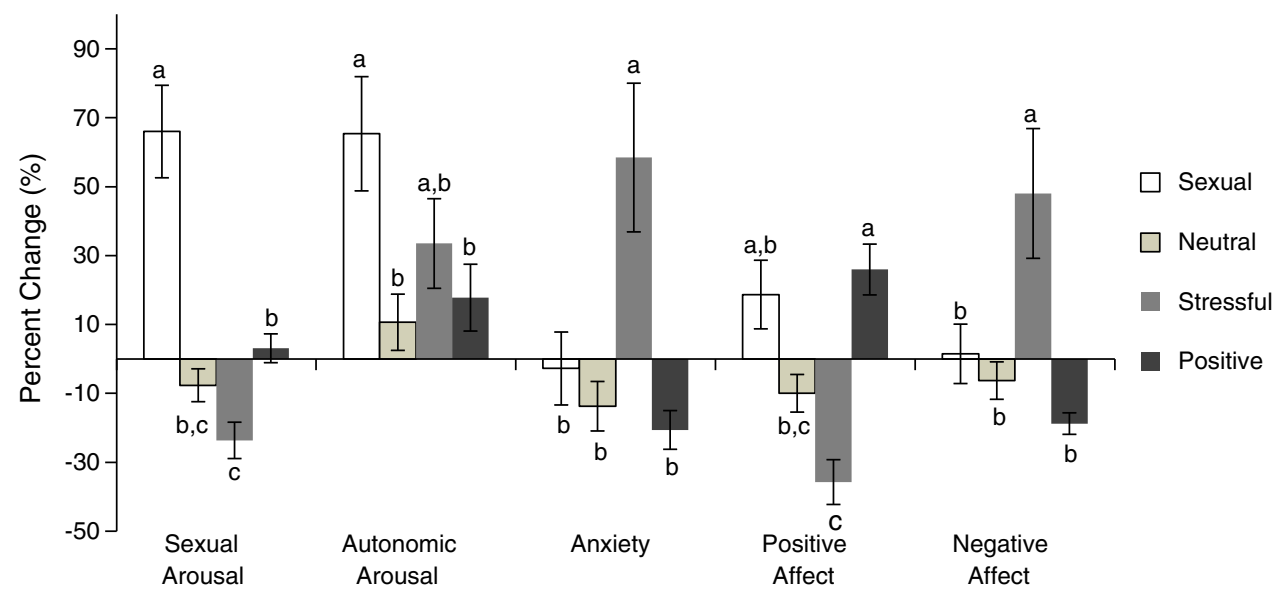

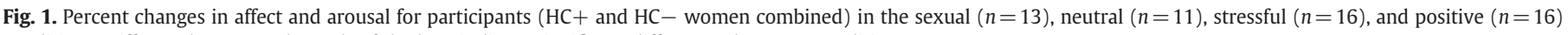
conditions. Different letters on the ends of the bars indicate significant differences between conditions at $p<0.05$.

$\mathrm{T} \%, F(3,47)=1.91, p=0.141$, nor was there a significant main effect of HCs on $\mathrm{T} \%, F(1,47)=0.15, p=0.704$. The effect was specific to $\mathrm{T}$, as $\mathrm{C} \%$ showed neither a significant interaction, $F(3,47)=1.07, p=0.370$, nor significant main effects of condition, $F(3,47)=0.14, p=0.938$, or HCs, $F$ $(1,47)=0.27, p=0.605$.

Because we found a significant overall effect, we conducted post hoc analyses to examine the interaction. For the $\mathrm{HC}-$ women, participants in the sexual condition had a significantly larger $\mathrm{T}$ increase than participants in the stressful condition, $t(18)=2.75$, $p=0.013$, and a trend for a larger increase compared to participants in the positive condition, $t(18)=2.03, p=0.057$. In contrast, for $\mathrm{HC}+$ women there was a trend for $\mathrm{T} \%$ to be lower in the sexual condition than in the stressful condition, $t(8)=2.20, p=0.059$, and there was no significant difference between the sexual and positive conditions in $\mathrm{T} \%, t(6)=0.66, p=0.535$. For HC+ women, participants in the stressful condition had significantly higher $\mathrm{T} \%$ than participants in the positive condition, $t(10)=3.40, p=0.007$. In sum, $\mathrm{T}$ increased in the sexual condition compared to the stressful and positive conditions for $\mathrm{HC}-$ women, but this was not true for $\mathrm{HC}+$ women. Instead, $\mathrm{HC}+$ women in the sexual condition had lower T\% than the stressful condition and similar T\% to the positive condition. See Fig. 2 for means and standard errors for T\% and Fig. 3 for C\%.

Table 1 provides a summary of absolute levels of $T$ and $C$ at baseline and post-activity in addition to percent changes in $\mathrm{T}$ and $\mathrm{C}$. The table shows the utility of comparing percent changes in hormones, which represent the change from baseline within an individual, rather than absolute levels, which simply reflect averages

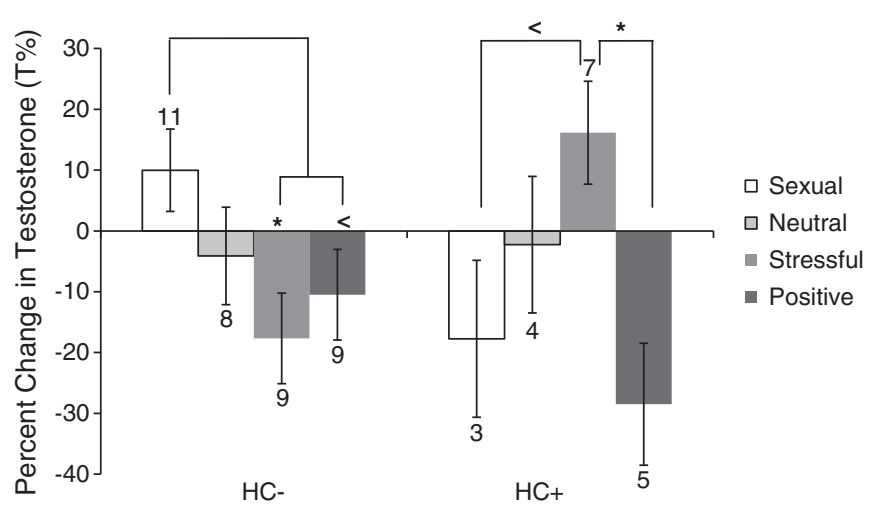

Fig. 2. Percent change in testosterone (T\%) by condition and HC use. '*' signifies a significant difference at $p<0.05$, and " $<$ " signifies a trend at $p<0.10$. Numbers at the end of each bar indicate $n$ 's for each group. Means and standard errors are adjusted for BMI. over the entire group. Within-person percent changes provide a more meaningful measure considering the varying sensitivities to hormone changes between individuals with different baselines. However, because controversy exists as to the most statistically appropriate method for calculating change scores from baseline (Allison, 1990; Cronbach and Furby, 1970), we re-conducted our analyses using an alternative method to calculate changes from baseline to post-activity, the regressor variable method (Allison, 1990). This approach has been used in the past to analyze hormone changes from baseline (Mehta and Josephs, 2006; Wirth et al., 2006). As per this method, change scores were calculated as the unstandardized residuals of a regression with T1 (or C1) as the predictor and T2 (or C2) as the dependent variable. These new change scores were then entered into the MANCOVA as the dependent variables, replacing percent change scores. Using this analysis, the multivariate interaction between condition and HCs was a trend, $F(6,92)=1.90, p=0.089$, as was the interaction of condition and HCs for T\%, $F(3,47)=2.45, p=0.076$, showing the same pattern of results as reported above for percent change. Therefore, results were similar using a different type of hormone change score.

\section{Correlations between hormones and changes in affect/arousal}

We were interested in condition-specific changes in arousal and hormones that might occur in parallel; e.g., increases in sexual arousal and $\mathrm{T}$ in the sexual condition, increases in anxiety and $\mathrm{C}$ in the stressful condition. We thus conducted within-condition correlations

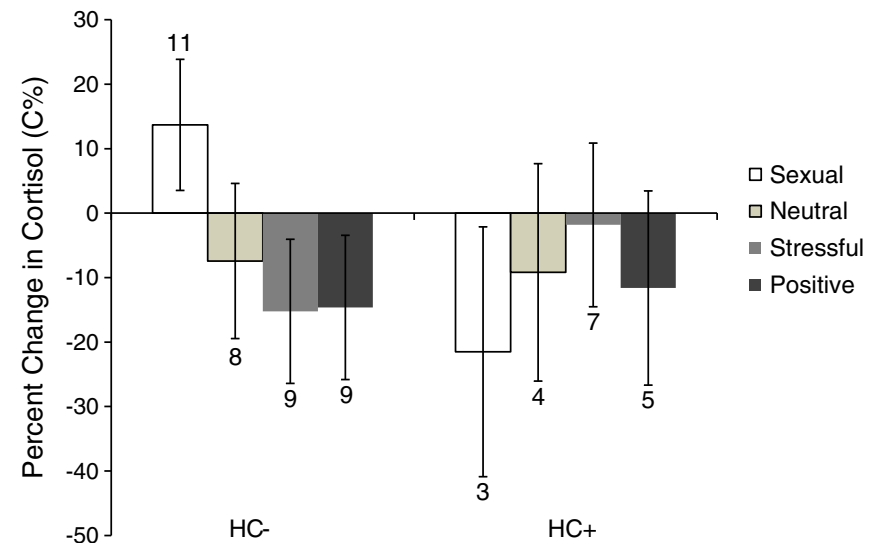

Fig. 3. Percent change in cortisol (C\%) by condition and HC use. Numbers at the end of each bar indicate $n$ 's for each group. Means and standard errors are adjusted for BMI. 
Table 1

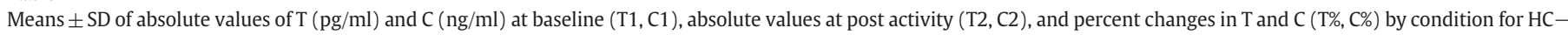
and $\mathrm{HC}+$ women. Values are adjusted for BMI.

\begin{tabular}{|c|c|c|c|c|c|c|c|}
\hline & & $\mathrm{T} 1$ & $\mathrm{~T} 2$ & $\mathrm{~T} \%$ & $\mathrm{C} 1$ & $\mathrm{C} 2$ & $\mathrm{C} \%$ \\
\hline \multirow[t]{4}{*}{$\mathrm{HC}-$} & Sexual & $14.10 \pm 5.97$ & $14.36 \pm 5.04$ & $9.98 \pm 26.67$ & $1.83 \pm 1.06$ & $1.89 \pm 1.03$ & $13.69 \pm 48.70$ \\
\hline & Neutral & $16.76 \pm 8.55$ & $15.12 \pm 6.43$ & $-4.12 \pm 19.74$ & $1.95 \pm 0.70$ & $1.80 \pm 0.80$ & $-7.42 \pm 29.28$ \\
\hline & Stressful & $15.94 \pm 8.55$ & $12.88 \pm 4.95$ & $-17.68 \pm 17.28$ & $1.75 \pm 1.08$ & $1.37 \pm 0.72$ & $-15.23 \pm 21.14$ \\
\hline & Positive & $18.95 \pm 8.79$ & $17.40 \pm 9.39$ & $-10.49 \pm 19.73$ & $1.60 \pm 0.97$ & $1.32 \pm 0.75$ & $-14.63 \pm 36.23$ \\
\hline \multirow[t]{4}{*}{$\mathrm{HC}+$} & Sexual & $6.68 \pm 2.09$ & $5.20 \pm 1.19$ & $-17.74 \pm 24.70$ & $1.62 \pm 0.71$ & $1.15 \pm 0.39$ & $-21.51 \pm 38.22$ \\
\hline & Neutral & $14.67 \pm 7.45$ & $14.86 \pm 9.73$ & $-2.27 \pm 18.29$ & $1.86 \pm 0.29$ & $1.71 \pm 0.60$ & $-9.19 \pm 30.89$ \\
\hline & Stressful & $8.08 \pm 3.97$ & $8.46 \pm 3.74$ & $16.15 \pm 30.13$ & $1.26 \pm 0.42$ & $1.20 \pm 0.29$ & $-1.83 \pm 19.83$ \\
\hline & Positive & $13.05 \pm 4.15$ & $9.81 \pm 4.16$ & $-28.50 \pm 10.31$ & $2.16 \pm 0.69$ & $1.90 \pm 0.59$ & $-11.62 \pm 14.77$ \\
\hline
\end{tabular}

between the relevant hormone and affect/arousal measure. All partial correlations reported here controlled for $\mathrm{HC}$ use.

\section{Sexual condition}

T\% was significantly negatively correlated with the percent change in subjective sexual arousal in response to sexual thoughts, partial $r(13)=-0.54, p=.039$ (see Fig. 4a). In contrast, T1 was significantly positively correlated with the change in subjective sexual arousal, partial $r(14)=0.62, p=0.01$ (see Fig. $4 \mathrm{~b}$ ). T2 was also significantly positively correlated with subjective sexual arousal, partial $r(14)=0.59, p=0.017$. Since T\% showed different patterns of correlation with arousal than T1 and T2, we correlated the three $\mathrm{T}$ measures, and found that $\mathrm{T} 1$ was significantly positively correlated with $\mathrm{T} 2$, partial $r(14)=0.75, p=0.001$, but significantly negatively correlated with T\%, partial $r(13)=-0.64, p=0.011$ (see Fig. 4c). T2 was not significantly correlated with T\%, partial $r(13)=$ $-0.09, p=0.750$. To check that the strong negative correlation between $\mathrm{T} 1$ and $\mathrm{T} \%$ was not due to a statistical artifact (i.e., regression to the mean), we correlated $\mathrm{T} 1$ and $\mathrm{T} \%$ in the positive condition and found no significant association, partial $r(14)=0.01, p=0.958$. Since the negative correlation was present in the sexual but not control condition, regression to the mean cannot explain the findings in the sexual condition (as it would equally affect both conditions). Accordingly, in the sexual condition, higher baseline $\mathrm{T}$ predicted larger increases in sexual arousal, but smaller increases in T, likely due to ceiling effects on the capacity of T to change. Including BMI as a covariate did not change the overall pattern of results, although some significant correlations decreased to trends, likely due to lower $d f$ 's.

None of the $\mathrm{T}$ measures ( $\mathrm{T} 1, \mathrm{~T} 2$, or $\mathrm{T} \%$ ) were significantly correlated with the percent change in autonomic arousal or anxiety. None of the $\mathrm{C}$ measures $(\mathrm{C} 1, \mathrm{C} 2$, or $\mathrm{C} \%$ ) were significantly correlated with the percent change in subjective sexual arousal, autonomic arousal, or anxiety for the sexual condition.

\section{Stressful condition}

There were no significant correlations between $\mathrm{T} 1, \mathrm{~T} 2$, or $\mathrm{T} \%$ and subjective sexual arousal, autonomic arousal, or anxiety in the stressful condition. There was a trend for a positive correlation between $\mathrm{C} 1$ and the percent change in autonomic arousal to imagining the stressful situation, partial $r(13)=0.51, p=0.054$, but this correlation decreased to a non-trend after controlling for BMI. The change in autonomic arousal was not significantly correlated with C2 or $\mathrm{C} \%$. There were no significant correlations between $\mathrm{C} 1, \mathrm{C} 2$, or $\mathrm{C} \%$ and the percent change in anxiety or subjective sexual arousal in the stressful condition.

Correlations between sexual experience and $T$ and $C$ responses to sexual thoughts

Because previous research suggests sexual experience facilitates $\mathrm{T}$ responses (Bonilla-Jaime et al., 2006; Kamel et al., 1975; Roney et al., 2003), we correlated sexual experience variables with hormonal responses in the sexual condition. For the items relevant to these analyses, sexual activity was defined as contact involving the participant's or another person's genitals. Again, all partial correlations reported here controlled for $\mathrm{HC}$ use, and for BMI in addition to $\mathrm{HC}$ use where indicated.

In the sexual condition, the length of time since a participant's most recent sexual experience (i.e., length of abstinence) was significantly positively correlated with $\mathrm{T} \%$, partial $r(13)=0.55$, $p=0.036$. Controlling for BMI reduced the correlation to a trend, partial $r(12)=0.52, p=0.059$. Thus, a greater length of time since the last sexual experience was correlated with a greater $\mathrm{T}$ increase in response to sexual thoughts.

The distribution of participants' number of lifetime sexual partners was skewed, so a log transformation was performed. T\% was significantly negatively correlated with the number of lifetime sexual partners, partial $r(13)=-0.59, p=0.021$. Controlling for BMI, the correlation remained significant, partial $r(12)=-0.55, p=0.042$. To examine whether the correlations of lifetime partners and length of abstinence with T\% might be due to participants with more lifetime partners or shorter length of abstinence having higher baseline $\mathrm{T}$, we correlated $\mathrm{T} 1$ with the sexual experience measures. T1 was not significantly correlated with length of abstinence, partial $r(14)=$ $-0.28, p=0.295$, or the number of lifetime partners, partial $r(14)=$ $0.33, p=0.210$, although both correlations were in the expected direction. See Table 2 for a summary of correlations between T, affect and arousal, and sexual experience in the sexual condition.

There were no significant correlations between $\mathrm{C} \%$ and length of time since sexual experience or number of lifetime partners. Participants with a longer length of abstinence or fewer lifetime partners displayed higher $\mathrm{T}$ responses to the sexual condition, but $\mathrm{C}$ responses were not related to sexual experience.

\section{Discussion}

In the present study, we examined effects of sexual cognitions on $\mathrm{T}$ and $\mathrm{C}$. We found that sexual thoughts increased $\mathrm{T}$ in $\mathrm{HC}-$ women. This $\mathrm{T}$ response to sexual cognitions occurred rapidly, within 15 minutes of imagining a sexual situation, in accordance with other findings showing $\mathrm{T}$ responses to social stimuli within 15-20 minutes of the stimulus (Hellhammer et al., 1985; Roney et al., 2003; van Anders et al., 2007). Previous research has demonstrated that the context of anticipating sexual activity increases $\mathrm{T}$ in women (Hamilton and Meston, 2010; van Anders et al., 2007), and our study is the first to provide experimental evidence that sexual thoughts increase T. For $\mathrm{HC}-$ women, thinking about a sexual situation increased $\mathrm{T}$ compared to thinking about a stressful or positive situation, indicating that neither the passage of time, stressful arousal, nor positive arousal were solely responsible for the change in $\mathrm{T}$. Thus, the $\mathrm{T}$ response is likely attributable, at least in part, to the sexually arousing nature of the cognitions.

Although viewing erotic stimuli does not appear to change $\mathrm{T}$ in women (Heiman et al., 1991; van Anders et al., 2009), our findings 

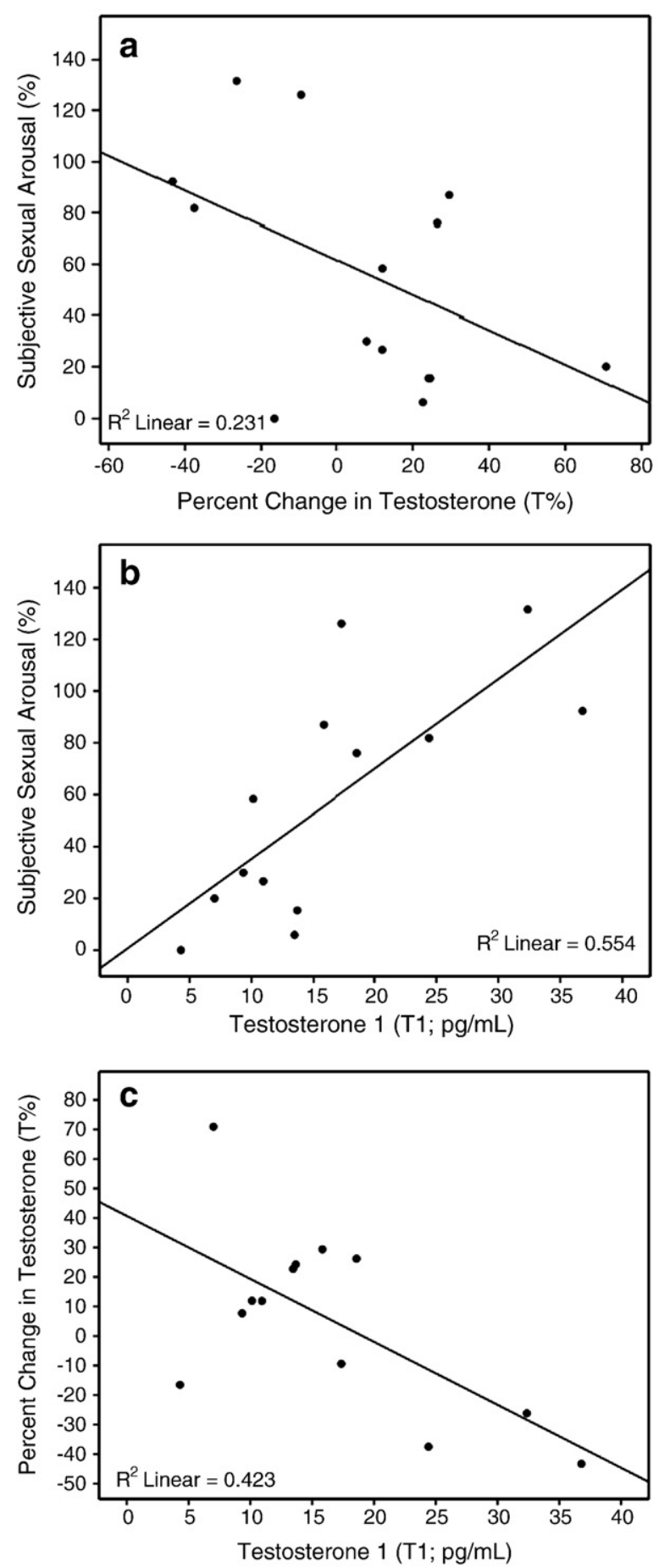

Fig. 4. Correlations in the sexual condition between a) percent change in $\mathrm{T}$ and percent change in subjective sexual arousal; b) T1 and percent change in subjective sexual arousal; and c) T1 and percent change in T. Figures include only HC- women.

suggest that sexual contexts need not always involve partners, sexual behavior, or orgasm to induce changes in T. Rather, it appears that women can influence their $\mathrm{T}$ levels by simply thinking sexual thoughts. Why would imagining a sexual encounter be more likely than erotic videos to change $\mathrm{T}$ in women? The stimuli depicted in erotic videos may not reflect real-life sexual experiences or preferences, and evidence indicates that preferred erotic stimuli increase psychological sexual arousal while non-preferred stimuli do not (though non-preferred stimuli can increase genital sexual arousal: Chivers and Bailey, 2005). It may be that psychological sexual arousal
Table 2

Correlations between $\mathrm{T}$ measures, affect and arousal variables, and sexual experience variables for participants in the sexual condition.

\begin{tabular}{llll}
\hline & $\mathrm{T} 1$ & $\mathrm{~T} 2$ & $\mathrm{~T} \%$ \\
\hline $\mathrm{T} 1$ & & $r(14)=0.75^{* *}$ & $r(13)=-0.64^{*}$ \\
$\mathrm{~T} 2$ & $r(14)=0.75^{* *}$ & & $r(13)=-0.09$ \\
$\mathrm{~T} \%$ & $r(13)=-0.64^{*}$ & $r(13)=-0.09$ & \\
Sexual arousal (\%) & $r(14)=0.62^{*}$ & $r(14)=0.59^{*}$ & $r(13)=-0.54^{*}$ \\
Auto arousal (\%) & $r(13)=0.29$ & $r(13)=0.33$ & $r(12)=-0.09$ \\
Anxiety (\%) & $r(13)=-0.15$ & $r(13)=-0.19$ & $r(12)=0.03$ \\
Length of abstinence & $r(14)=-0.28$ & $r(14)=0.06$ & $r(13)=0.55^{*}$ \\
Number partners & $r(14)=0.33$ & $r(14)=0.07$ & $r(13)=-0.59^{*}$ \\
\hline
\end{tabular}

Note. ${ }^{\text {**' }}$ indicates a significant correlation at $p<0.05$, and '**' indicates $p<0.01$. All correlations are partial correlations controlling for HCs.

is necessary for a sexual experience to increase T. Accordingly, a major strength of the ISSE is that participants imagine content that they find arousing, however idiosyncratic that content may be. Indeed, past studies have found that hormonal responses to erotic films differ from responses to sexual activity (van Anders et al., 2007, 2009), and our findings suggest that imagining a sexual encounter produces a similar $T$ response to actually engaging in sexual behavior (van Anders et al., 2007). Thus, perception of a situation as sexual appears to be a critical factor for modulation of $\mathrm{T}$ to occur.

Importantly, $\mathrm{HC}$ use moderated the $\mathrm{T}$ response to sexual thoughts. In contrast to the results for $\mathrm{HC}$ - women, $\mathrm{HC}+$ women showed decreased $\mathrm{T}$ in the sexual condition compared to the stressful condition and no difference in $\mathrm{T}$ between the sexual and positive conditions. These findings are similar to those of Lopez et al. (2009), who found that watching a video depicting an attractive man increased $\mathrm{T}$ only in women not using HCs. In the current study, HC+ women also exhibited increased $\mathrm{T}$ responses to stressful stimuli relative to $\mathrm{HC}$ - women. Why $\mathrm{HC}$ use reversed $\mathrm{T}$ responses to sexual and stressful stimuli is not certain; similar mechanisms could account for effects of HCs on T responses and baseline $\mathrm{T}$ (i.e., inhibition of gonadotropin secretion), but this explanation does not fully clarify why $\mathrm{T}$ responses were reversed rather than dampened. Alternatively, as we did not manipulate HC status, HCand $\mathrm{HC}+$ women may have differed on one or more pre-existing variables which could account for the variation in responses. Although mechanism is still unclear, our data point to the importance of addressing HC use as a variable of interest in studies involving hormonal responses. The effect of HCs on T responses may depend on the type of social stimulus, considering that $\mathrm{HC}$ use does not affect $\mathrm{T}$ responses to athletic competition (Edwards and O'Neal, 2009), but appears to affect T responses to sexual or stressful thoughts. As suggested by Josephs (2009), future research could involve larger samples in order to examine how variability due to length of $\mathrm{HC}$ use and type of $\mathrm{HC}$ affects $\mathrm{T}$ responses to sexual stimuli.

Sexual thoughts did not change $C$, indicating that the hormonal response to sexual cognitions was specific to $\mathrm{T}$ and not due to general physiological arousal. The fact that sexual thoughts elicited rapid $\mathrm{T}$ release but no change in $C$ provides a clue to the mechanism for the $T$ response. In women, $\mathrm{T}$ may be released from the ovaries or the adrenal glands (Nelson, 2005), and the lack of a C response points to the ovary as a more likely source of the T, as HPA activation would presumably have triggered $C$ release as well. Activation of the HPG cascade, or possibly neural projections to the ovary from the brain (Gerendai et al., 2002), could have triggered T release. As suggested by previous authors (Edwards and O'Neal, 2009), the fact that HCs disrupted $\mathrm{T}$ responses also suggests involvement of the HPG axis in this response. Clearly, such arguments are speculative, and further research, particularly with nonhuman species, is needed to determine the source of $\mathrm{T}$ responses to social stimuli in females.

The role of $C$ in sexual contexts remains elusive, as previous studies involving visual erotic stimuli in women have reported a decrease in C (van Anders et al., 2009), a decrease in C for the majority of 
participants and an increase for a minority (Hamilton et al., 2008), or no change (Exton et al., 2000; Heiman et al., 1991). Of course, C may respond differently depending on whether the situation involves sexual activity, visual stimuli, or sexual thoughts. Although participants reported feeling anxious in response to the stressful condition, $C$ did not increase in this condition, though other forms of psychological stress can increase C (Kirschbaum et al., 1993). Imagining a sexual situation was a strong enough stimulus to change $\mathrm{T}$, but previous studies have employed an audience to heighten the saliency of a stressful stimulus, and it may be that imagining a stressful situation without an audience was not stressful enough to elicit a substantial change in $\mathrm{C}$.

We found that baseline $\mathrm{T}$ and $\mathrm{T}$ changes in the sexual condition were associated with self-reported sexual arousal in different ways. Baseline $T$ was positively correlated with sexual arousal, but $T$ changes were negatively correlated with arousal. Our study, along with previous studies reporting associations between baseline $T$ and perceived autonomic arousal (van Anders et al., 2009) or perceived vaginal lubrication (Myers and Morokoff, 1986), provides support for a role for basal $\mathrm{T}$ in regulation of subjective sexual arousal. Although the mechanism for the link between baseline $\mathrm{T}$ and sexual arousal is unknown, T may increase arousal at the genital level by up-regulating synthesis of nitric oxide and relaxation of smooth muscle in the vagina (Traish et al., 2002), or at the level of the brain by activating areas involved in perception of sexual arousal (Stoleru et al., 1999). Furthermore, as our findings are correlational, a reverse association cannot be ruled out; i.e., repeatedly experiencing high levels of sexual arousal could lead to elevated basal T. Regardless, these data highlight the value of considering multiple dimensions of hormone measures (i.e., baselines vs. changes) as conceptually distinct.

The different associations of arousal with baseline $\mathrm{T}$ versus $\mathrm{T}$ changes can be explained by the negative correlation between baseline $\mathrm{T}$ and the change in $\mathrm{T}$, which supports predictions based on the Challenge Hypothesis (Wingfield et al., 1990). According to this hypothesis, the amount of $\mathrm{T}$ increase is limited by a physiological maximum for $\mathrm{T}$, so individuals with lower baseline $\mathrm{T}$ experience larger changes in T in response to socially relevant stimuli (Wingfield et al., 1990). Although the Challenge Hypothesis was developed mainly through research with male birds, our recent data (van Anders and Brotto, under review) indicate that ceiling effects on $T$ occur for women related to sexual stimulation of $\mathrm{T}$ as well. Because the significant association between $\mathrm{T} 1$ and $\mathrm{T} \%$ was unique to the sexual condition, our findings cannot be explained by regression to the mean (which would be equally visible in all conditions if it were the cause of the negative correlation) (Barnett et al., 2005), and instead represent real physiological change. It is noteworthy that the lower baseline levels of $\mathrm{T}$ in the $\mathrm{HC}+$ women corresponded to lower rather than higher $\mathrm{T}$ responses, indicating that endogenous vs. exogenous low baseline $\mathrm{T}$ may affect $\mathrm{T}$ changes differently.

Similar to previous studies (Bonilla-Jaime et al., 2006; Kamel et al., 1975; Roney et al., 2003), we found that sexual experience was related to sexually-stimulated changes in T. However, our results differ from these studies in that we found that recent sexual experience was linked to lower (rather than higher) $\mathrm{T}$ responses. Previous studies have reported negative correlations between baseline $\mathrm{T}$ and frequency of partnered sexual activity in women (van Anders and Goldey, 2010) and occurrence of sexual activity in the last month in men (van der Meij et al., 2008), but we did not find an association between baseline $T$ and recency of sexual activity in our sample. Our results are similar to those of Exton et al. (2001), who found that although baseline T levels did not differ between men who had experienced a 3-week period of abstinence and men who had not abstained from sexual activity, $\mathrm{T}$ was higher immediately before and during presentation of an erotic video and masturbation to orgasm in the men who had abstained. The authors interpreted this difference as an elevated anticipatory rise in $\mathrm{T}$ after a period of abstinence (Exton et al., 2001), and a similar interpretation may be true for our findings. Abstinence, along with frequency of sexuality, thus appears to be an important modulator of $\mathrm{T}$ responses to sexual contexts.

Our newly developed method, the ISSE, possesses several key strengths as a tool to elicit sexual arousal. Unlike stimuli such as videos or pictures, the ISSE allows participants to self-define the type of person attractive to them, without limiting the target of arousal to a person of a particular race/ethnicity, gender, age, body type, etc. Participants can also tailor the types of sexual behaviors and degree of explicitness they imagine to fit their individual preferences and comfort levels. Thus, the ISSE is uniquely suited for inclusion of sexual, ethnic, and gender diversity, and the ability to self-select an arousing situation may increase psychological arousal by decreasing negative affect associated with erotica (Laan et al., 1994; Laan and Janssen, 2007). Furthermore, as the ISSE requires participants to write about their imagined situation, it may increase their levels of absorption and engagement with the sexual material, contributing to higher sexual arousal (Follingstad and Kimbrell, 1986; Koukounas and Over, 1997). The use of open-ended questions to cue participants' responses helps control certain aspects of imagined situations across participants while still allowing for flexibility in responses.

In addition to strengths, the ISSE also has limitations, one of which is the difficulty of selecting an appropriate prompt for the neutral condition. Contrary to our expectations, we did not find a difference in the $\mathrm{T}$ response between the sexual and neutral conditions. Analysis of neutral responses revealed some heterogeneity in valence, as some participants provided positive or negative reports rather than only neutral as asked. Although participants in the neutral condition were instructed to imagine an "ordinary" encounter at the post office, and many participants did provide neutral content, this condition elicited more variable responses than the other conditions, and it may be difficult to have all participants imagine truly "neutral" content. Furthermore, although our non-sexual conditions controlled for several characteristics of imagined sexual situations, including affiliation, reward, stress, and imagining a social interaction, we did not control for some aspects of an imagined situation besides sexual arousal (e.g., thinking about physical contact) that might have contributed to hormonal responses. Finally, the ISSE is a new method and further testing will help extend its reliability and validity; however, we conducted many manipulation checks (e.g., thematic coding, affect and arousal scores); these, along with the hormonal responses, support its utility in producing both sexual arousal and endocrine responses.

Other limitations of our study include the relatively small sample sizes for the $\mathrm{HC}+$ groups and for within-condition correlations. The wide variability in hormonal responses within conditions, especially for C, is also worth noting, and may have limited our ability to see significant effects. Future studies with larger sample sizes could more thoroughly examine the sources of individual variability in $T$ and $C$ responses to sexual thoughts. The finding that thinking about sex affects $\mathrm{T}$ provides exciting possibilities for future research. The function of this $\mathrm{T}$ response is uncertain, but given that higher $\mathrm{T}$ is associated with more attention to sexual stimuli (Rupp and Wallen, 2007) and decreased anxiety (Bouissou and Vandenheede, 1996; Vandenheede and Bouissou, 1993), perhaps the T response to sexual thoughts facilitates future sexual encounters by increasing sexual motivation or decreasing inhibition. Because androgens have rewarding properties (Alexander et al., 1994; Jorge et al., 2005; Wood, 2004), imagining positive sexual encounters and the resulting $T$ responses might even increase enjoyment of subsequent sexual behavior. Considering that men show T responses to sexual stimuli (Hellhammer et al., 1985; Redoute et al., 2000; Rowland et al., 1987; Stoleru et al., 1999), and that sexual modulation of $\mathrm{T}$ is similar across genders in certain situations (e.g., sexual activity: Dabbs and Mohammed, 1992) but divergent in others (e.g., exposure to visual stimuli: Stoleru et al., 1999; van Anders et al., 2009), it remains to be seen whether men will 
show similar or different effects of sexual thoughts on $\mathrm{T}$ compared to women.

Many questions remain regarding hormonal responses to sexual thoughts: Is thinking about sexual activity in a certain way (e.g., positively as in the current study) required for the T response? Would the effects on T extend to any sexual fantasy, or only to thoughts about an encounter with an attractive person? Can just thinking about an attractive person change $\mathrm{T}$, or is imagining sexual behavior necessary as well? How might variations in imagined scenarios (e.g., sexual thoughts with the presence or absence of romantic thoughts) relate to $\mathrm{T}$ ? Although we found that sexual thoughts did not affect $\mathrm{C}$, might they affect other hormones besides $\mathrm{T}$ (e.g., estradiol, oxytocin, prolactin)? Our results indicate that sexual thoughts change $\mathrm{T}$, baseline T levels and $\mathrm{HC}$ use affect the magnitude and direction of the $T$ response, and cognitive aspects of arousal contribute to sexual modulation of hormones.

\section{Acknowledgments}

We thank N. Caverly, N. Desai, J. Eisman, S. Greenberg, L. Hipp, S. Massuch, S. Ngo, R. O'Hara, K. Ruelle, and J. Stein for help with data collection and Dr. A. Lu for conducting testosterone assays and providing helpful advice on salivary assay methods.

\section{Appendix}

\section{Instructions for Prompt:}

Note: Instructions below were for the sexual condition, and words in brackets indicate alternate text for the neutral, stressful, and positive conditions respectively.

The next section of this questionnaire will ask you to imagine a sexually arousing [ordinary social/ stressful social/ pleasant social] situation based on the scenario described below. The questions that follow on the next page will ask you to describe various aspects of the situation that you are imagining. Please try to imagine the situation in as much detail as possible, and imagine feeling sexually aroused [as you would in an ordinary and routine situation/ stressed/ happy and excited]. Please take a few moments to imagine yourself in this situation. When you are ready, you may click below to advance to the next page.

\section{Instructions for Questions:}

Please respond to the following questions while imagining yourself in the situation below. Your responses will be kept completely confidential. A suggested response amount for each question is $2-3$ sentences, but feel free to include more information if you wish.

\section{Sexual condition}

Imagine that you have met a person who is sexually attractive to you, and you and this person decide to engage in sexual activity together. You find your sexual partner very attractive, and you enjoy the sexual activity very much. Consider your sexual partner, your feelings of attraction, how you start being sexual, and the sexual activity itself.

1. Describe your sexual partner as vividly as possible. Feel free to include physical characteristics, personality traits, etc.

2. Describe your feelings of attraction toward this person.

3. Describe the location of your interaction with this person and how you feel being in this location.

4. Describe the situation and background events leading up to the sexual activity.

5. How do you and your sexual partner start being sexual together?

6 . Describe the sexual activity itself.

7. What about this interaction makes it sexually arousing for you?
8. Please describe any other details and/or aspects of the interaction not included in your responses to the above questions.

\section{Neutral condition}

Imagine that you are mailing a package at the post office, and you interact with a post office employee as you mail your package. You find the postal worker ordinary, and you find your visit to the post office routine. Consider the postal worker, your feelings toward this person, and your interaction with the postal worker as you mail your package.

1. Describe the postal worker as vividly as possible. Feel free to include physical characteristics, personality traits, etc.

2. Describe your feelings toward this person.

3. Describe the location of your interaction with this person and how you feel being in this location.

4. Describe the situation and background events leading up to your interaction with the postal worker.

5. How do you and the postal worker begin your interaction?

6 . Describe your interaction with the postal worker as you mail your package.

7. What about this interaction makes it feel ordinary to you?

8. Please describe any other details and/or aspects of the interaction not included in your responses to the above questions.

\section{Stressful condition}

Imagine that you arrive for a job interview for a competitive position. You meet the interviewer, a cold individual who responds to you in a skeptical, judgmental manner. You find the interview stressful in nature. Consider the interviewer, your feelings toward this person, how the interview begins, and the interview itself.

1. Describe the interviewer as vividly as possible. Feel free to include physical characteristics, personality traits, etc.

2. Describe your feelings toward this person.

3. Describe the location of your interaction with this person and how you feel being in this location.

4. Describe the situation and background events leading up to your interview.

5. How does the interview begin?

6 . Describe the interview itself.

7. What about this interaction makes it stressful for you?

8. Please describe any other details and/or aspects of the interaction not included in your responses to the above questions.

\section{Positive condition}

Imagine that you just received the good news that you have been accepted for a position you applied for. You encounter a close friend of yours and tell your friend the news, and you and your friend decide to spend time together and celebrate. Consider your friend, your feelings toward this person, telling your friend the good news, and celebrating with your friend.

1. Describe your friend as vividly as possible. Feel free to include physical characteristics, personality traits, etc.

2. Describe your feelings toward this person.

3. Describe the location of your interaction with this person and how you feel being in this location.

4. Describe the situation and background events leading up to your interaction with your friend.

5 . How do you tell your friend your good news?

6. Describe celebrating your good news together with your friend.

7. What about this interaction makes it pleasant for you?

8. Please describe any other details and/or aspects of the interaction not included in your responses to the above questions. 


\section{References}

Alexander, G.M., Packard, M.G., Hines, M., 1994. Testosterone has rewarding affective properties in male rats: implications for the biological basis of sexual motivation. Behav. Neurosci. 108, 424-428.

Allison, P.D., 1990. Change scores as dependent variables in regression analysis Sociological Methodology 20, 93-114.

Anonymous, 1970. Effects of sexual activity on beard growth in man. Nature 226 869-870.

Axelsson, J., Ingre, M., Akerstedt, T., Holmback, U., 2005. Effects of acutely displaced sleep on testosterone. J. Clin. Endocrinol. Metab. 90, 4530-4535.

Bancroft, J., 2005. The endocrinology of sexual arousal. J. Endocrinol. 186, 411-427.

Bancroft, J., Sherwin, B.B., Alexander, G.M., Davidson, D.W., Walker, A., 1991. Oral contraceptives, androgens, and the sexuality of young women: II. The role of androgens. Arch. Sex. Behav. 20, 121-135.

Barnett, A.G., van der Pols, J.C., Dobson, A.J., 2005. Regression to the mean: what it is and how to deal with it. Int. J. Epidemiol. 34, 215-220.

Bonilla-Jaime, H., Vazquez-Palacios, G., Arteaga-Silva, M., Retana-Marquez, S., 2006. Hormonal responses to different sexually related conditions in male rats. Horm. Behav. 49, 376-382.

Bouissou, M.F., Vandenheede, M., 1996. Long-term effects of androgen treatment on fear reactions in ewes. Horm. Behav. 30, 93-99.

Burger, H.G., Dudley, E.C., Cui, J., Dennerstein, L., Hopper, J.L., 2000. A prospective longitudinal study of serum testosterone, dehydroepiandrosterone sulfate, and sex hormone-binding globulin levels through the menopause transition. J. Clin. Endocrinol. Metab. 85, 2832-2838.

Campbell, K.L., Schultheiss, O.C., McClelland, D.C., 1999. A necessary adjustment of protocol for use of DPC coat-a-count total testosterone assay with saliva. Clin. Biochem. 32, 83-85.

Carre, J.M., Gilchrist, J.D., Morrissey, M.D., McCormick, C.M., 2010. Motivational and situational factors and the relationship between testosterone dynamics and human aggression during competition. Biol. Psychol. 84, 346-353.

Carre, J.M., Putnam, S.K., 2010. Watching a previous victory produces an increase in testosterone among elite hockey players. Psychoneuroendocrinology 35, 475-479.

Chivers, M.L., Bailey, J.M., 2005. A sex difference in features that elicit genital response. Biol. Psychol. 70, 115-120.

Coenen, C.M., Thomas, C.M., Borm, G.F., Hollanders, J.M., Rolland, R., 1996. Changes in androgens during treatment with four low-dose contraceptives. Contraception 53 , $171-176$.

Cronbach, L.J., Furby, L., 1970. How should we measure "change"-or should we. Psychol. Bull. 74, 68-80.

Dabbs Jr., J.M., de La Rue, D., 1991. Salivary testosterone measurements among women: relative magnitude of circadian and menstrual cycles. Horm. Res. 35, 182-184.

Dabbs Jr., J.M., Mohammed, S., 1992. Male and female salivary testosterone concentrations before and after sexual activity. Physiol. Behav. 52, 195-197.

Dekker, J., Everaerd, W., 1988. Attentional effects on sexual arousal. Psychophysiology $25,45-54$

Dickerson, S.S., Kemeny, M.E., 2004. Acute stressors and cortisol responses: a theoretical integration and synthesis of laboratory research. Psychol. Bull. 130, 355-391.

Edwards, D.A., O'Neal, J.L., 2009. Oral contraceptives decrease saliva testosterone but do not affect the rise in testosterone associated with athletic competition. Horm. Behav. 56, 195-198.

Edwards, D.A., Wetzel, K., Wyner, D.R., 2006. Intercollegiate soccer: saliva cortisol and testosterone are elevated during competition, and testosterone is related to status and social connectedness with team mates. Physiol. Behav. 87, 135-143.

Exton, M.S., Bindert, A., Kruger, T., Scheller, F., Hartmann, U., Schedlowski, M., 1999. Cardiovascular and endocrine alterations after masturbation-induced orgasm in women. Psychosom. Med. 61, 280-289.

Exton, M.S., Kruger, T.H., Bursch, N., Haake, P. Knapp, W., Schedlowski, M., Hartmann, U., 2001. Endocrine response to masturbation-induced orgasm in healthy men following a 3-week sexual abstinence. World J. Urol. 19, 377-382.

Exton, N.G., Truong, T.C., Exton, M.S., Wingenfeld, S.A., Leygraf, N., Saller, B., Hartmann, U., Schedlowski, M., 2000. Neuroendocrine response to film-induced sexual arousal in men and women. Psychoneuroendocrinology 25, 187-199.

Follingstad, D.R., Kimbrell, C.D., 1986. Sex fantasies revisited: An expansion and further clarification of variables affecting sex fantasy production. Arch. Sex. Behav. 15, 475-486.

Gerendai, I., Kocsis, K., Halasz, B., 2002. Supraspinal connections of the ovary: Structural and functional aspects. Microsc. Res. Tech. 59, 474-483.

Graham, J.M., Desjardins, C., 1980. Classical conditioning: induction of luteinizing hormone and testosterone secretion in anticipation of sexual activity. Science 210 , 1039-1041.

Granger, D.A., Shirtcliff, E.A., Booth, A., Kivlighan, K.T., Schwartz, E.B., 2004. The "trouble" with salivary testosterone. Psychoneuroendocrinology 29, 1229-1240.

Greco, T., Graham, C.A., Bancroft, J., Tanner, A., Doll, H.A., 2007. The effects of ora contraceptives on androgen levels and their relevance to premenstrual mood and sexual interest: a comparison of two triphasic formulations containing norgestimate and either 35 or 25 microg of ethinyl estradiol. Contraception 76, 8-17.

Hamilton, L.D., Meston, C.M., 2010. The effects of partner togetherness on salivary testosterone in women in long distance relationships. Horm. Behav. 57, 198-202.

Hamilton, L.D., Rellini, A.H., Meston, C.M., 2008. Cortisol, sexual arousal, and affect in response to sexual stimuli. J. Sex. Med. 5, 2111-2118.

Heiman, J.R., Rowland, D.L., Hatch, J.P., Gladue, B.A., 1991. Psychophysiological and endocrine responses to sexual arousal in women. Arch. Sex. Behav. 20, 171-186.

Heiman, J.R., Rowland, D.L., 1983. Affective and physiological sexual response patterns: the effects of instructions on sexually functional and dysfunctional men. J. Psychosom. Res. 27, 105-116.
Hellhammer, D.H., Hubert, W., Schurmeyer, T., 1985. Changes in saliva testosterone after psychological stimulation in men. Psychoneuroendocrinology 10, 77-81.

Hinshelwood, S., 1997. Scotland: The Beauty and Majesty [Film]. Point Two Ltd., Richmond Hill, ON. (Director)

Janssen, E., Carpenter, D., Graham, C.A., 2003. Selecting films for sex research: gender differences in erotic film preference. Arch. Sex. Behav. 32, 243-251.

Jorge, J.C., Velazquez, K.T., Ramos-Ortolaza, D.L., Lorenzini, I., Marrero, J., Maldonado-Vlaar, C.S., 2005. A testosterone metabolite is rewarding to ovariectomized female rats. Behav. Neurosci. 119, 1222-1226.

Josephs, R.A., 2009. Moving beyond dichotomies in research on oral contraceptives: a comment on Edwards and O'Neal. Horm. Behav. 56, 193-194.

Kamel, F., Mock, E.J., Wright, W.W., Frankel, A.I., 1975. Alterations in plasma concentrations of testosterone, $\mathrm{LH}$, and prolactin associated with mating in the male rat. Horm. Behav. 6, 277-288.

Khan-Dawood, F.S., Choe, J.K., Dawood, M.Y., 1984. Salivary and plasma bound and "free" testosterone in men and women. Obstet. Gynecol. 148, 441-445.

Kirschbaum, C., Kudielka, B.M., Gaab, J., Schommer, N.C., Hellhammer, D.H., 1999. Impact of gender, menstrual cycle phase, and oral contraceptives on the activity of the hypothalamus-pituitary-adrenal axis. Psychosom. Med. 61, 154-162.

Kirschbaum, C., Pirke, K.M., Hellhammer, D.H., 1993. The "Trier Social Stress Test"-a tool for investigating psychobiological stress responses in a laboratory setting. Neuropsychobiology 28, 76-81.

Koukounas, E., Over, R., 1997. Male sexual arousal elicited by film and fantasy matched in content. Aust. J. Psychol. 49, 1-5.

Kudielka, B.M., Kirschbaum, C., 2003. Awakening cortisol responses are influenced by health status and awakening time but not by menstrual cycle phase. Psychoneuroendocrinology 28, 35-47.

Laan, E., Everaerd, W., van Bellen, G., Hanewald, G., 1994. Women's sexual and emotional responses to male- and female-produced erotica. Arch. Sex. Behav. 23, 153-169.

Laan, E., Janssen, E., 2007. How do men and women feel? Determinants of subjective experience of sexual arousal. In: Janssen, E. (Ed.), The Psychophysiology of Sex. Indiana University Press, Bloomington, pp. 278-290.

LaFerla, J.J., Anderson, D.L., Schalch, D.S., 1978. Psychoendocrine response to sexual arousal in human males. Psychosom. Med. 40, 166-172.

Lippi, G., De Vita, F., Salvagno, G., Gelati, M., Montagnana, M., Guidi, G., 2009 Measurement of morning saliva cortisol in athletes. Clin. Biochem. 42, 904-906.

Lo, M.S., Ng, M.L., Azmy, B.S., Khalid, B.A., 1992. Clinical applications of salivary cortisol measurements. Singapore Med. J. 33, 170-173.

Lopez, H.H., Hay, A.C., Conklin, P.H., 2009. Attractive men induce testosterone and cortisol release in women. Horm. Behav. 56, 84-92.

Loving, T.J., Crockett, E.E., Paxson, A.A., 2009. Passionate love and relationship thinkers: experimental evidence for acute cortisol elevations in women. Psychoneuroendocrinology 34, 939-946.

Magrini, G., Chiodoni, G., Rey, F., Felber, J.P., 1986. Further evidence for the usefulness of the salivary testosterone radioimmunoassay in the assessment of androgenicity in man in basal and stimulated conditions. Hormone Research in Paediatrics 23, 65-73.

McCormick, C.M., Teillon, S.M., 2001. Menstrual cycle variation in spatial ability: relation to salivary cortisol levels. Horm. Behav. 39, 29-38.

Mehta, P.H., Josephs, R.A., 2006. Testosterone change after losing predicts the decision to compete again. Horm. Behav. 50, 684-692.

Murphy, A., Cropp, C.S., Smith, B.S., Burkman, R.T., Zacur, H.A., 1990. Effect of low-dose oral contraceptive on gonadotropins, androgens, and sex hormone binding globulin in nonhirsute women. Fertil. Steril. 53, 35-39.

Myers, L.S., Morokoff, P.J., 1986. Physiological and subjective sexual arousal in pre- and postmenopausal women and postmenopausal women taking replacement therapy. Psychophysiology 23, 283-292.

National Commission on Culture and the Arts (Philippines), 2003. Manila: Uptown and Downtown [Film]. Manila: National Commission for Culture and the Arts.

Nelson, R.J., 2005. An Introduction to Behavioral Endocrinology. Sinauer Associates, Sunderland, Mass.

Odber, J., Cawood, E.H., Bancroft, J., 1998. Salivary cortisol in women with and without perimenstrual mood changes. J. Psychosom. Res. 45, 557-568.

Quissell, D.O., 1993. Steroid hormone analysis in human saliva. Ann. N.Y. Acad. Sci. 694 $143-145$

Redoute, J., Stoleru, S., Gregoire, M.C., Costes, N., Cinotti, L., Lavenne, F., Le Bars, D. Forest, M.G., Pujol, J.F., 2000. Brain processing of visual sexual stimuli in human males. Hum. Brain Mapp. 11, 162-177.

Regan, P.C., 1999. Hormonal correlates and causes of sexual desire: A review. Can. J. Hum. Sex. 8, 1-16.

Roney, J., Mahler, S.V., Maestripieri, D., 2003. Behavioral and hormonal responses of men to brief interactions with women. Evol. Hum. Behav. 24, 365-375.

Roney, J.R., Lukaszewski, A.W., Simmons, Z.L., 2007. Rapid endocrine responses of young men to social interactions with young women. Horm. Behav. 52, 326-333.

Rosen, R., Beck, J.G., 1988. Patterns of sexual response. In: Rosen, R., Beck, J.G. (Eds.) Patterns of Sexual Arousal: Psychophysiological Processes and Clinical Applications. Guilford Press, New York, pp. 23-52.

Rowland, D.L., Heiman, J.R., Gladue, B.A., Hatch, J.P. Doering C.H. Weiler S.J. 1987. Endocrine, psychological and genital response to sexual arousal in men. Psychoneuroendocrinology 12, 149-158.

Rupp, H.A., Wallen, K., 2007. Relationship between testosterone and interest in sexua stimuli: the effect of experience. Horm. Behav 52, 581-589.

Schultheiss, O.C., Dargel, A., Rohde, W., 2003. Implicit motives and gonadal steroid hormones: effects of menstrual cycle phase, oral contraceptive use, and relationship status. Horm. Behav. 43, 293-301.

Schultheiss, O.C., Rohde, W., 2002. Implicit power motivation predicts men's testosterone changes and implicit learning in a contest situation. Horm. Behav. 41, 195-202. 
Schultheiss, O.C., Wirth, M.M., Stanton, S.J., 2004. Effects of affiliation and power motivation arousal on salivary progesterone and testosterone. Horm. Behav. 46, 592-599.

Shirtcliff, E.A., Granger, D.A., Likos, A., 2002. Gender differences in the validity of testosterone measured in saliva by immunoassay. Horm. Behav. 42, 62-69.

Stoleru, S., Gregoire, M.C., Gerard, D., Decety, J., Lafarge, E., Cinotti, L., Lavenne, F., Le Bars, D., Vernet-Maury, E., Rada, H., Collet, C., Mazoyer, B., Forest, M.G., Magnin, F. Spira, A., Comar, D., 1999. Neuroanatomical correlates of visually evoked sexual arousal in human males. Arch. Sex. Behav. 28, 1-21.

Swinkels, L.M., Meulenberg, P.M., Ross, H.A., Benraad, T.J., 1988. Salivary and plasma free testosterone and androstenedione levels in women using oral contraceptives containing desogestrel or levonorgestrel. Ann. Clin. Biochem. 25, 354-359.

Thorneycroft, I.H., Stanczyk, F.Z., Bradshaw, K.D., Ballagh, S.A., Nichols, M., Weber, M.E., 1999. Effect of low-dose oral contraceptives on androgenic markers and acne. Contraception 60, 255-262.

Toledano, R., Pfaus, J., 2006. The sexual arousal and desire inventory (SADI): a multidimensional scale to assess subjective sexual arousal and desire. J. Sex. Med. 3, 853-877.

Traish, A.M., Kim, N., Min, K., Munarriz, R., Goldstein, I., 2002. Role of androgens in female genital sexual arousal: receptor expression, structure, and function. Fertil. Steril. 77 (Suppl 4), S11-8.

van Anders, S.M., Brotto, L., under review. Supporting the Challenge Hypothesis and negative feedback: Baseline steroids are positively correlated with within- and between-steroid changes.

van Anders, S.M., Brotto, L., Farrell, J., Yule, M., 2009. Associations among physiologica and subjective sexual response, sexual desire, and salivary steroid hormones in healthy premenopausal women. J. Sex. Med. 6, 739-751.

van Anders, S.M., Hamilton, L.D., Schmidt, N., Watson, N.V., 2007. Associations between testosterone secretion and sexual activity in women. Horm. Behav. 51, 477-482. van Anders, S.M., Goldey, K.L., 2010. Testosterone and partnering are linked via relationship status for women and 'relationship orientation' for men. Horm. Behav. 58, 820-826.

van Anders, S.M., Watson, N.V., 2006a. Menstrual cycle irregularities are associated with testosterone levels in healthy premenopausal women. Am. J. Hum. Biol 18, 841-844.

van Anders, S.M., Watson, N.V., 2006b. Relationship status and testosterone in North American heterosexual and non-heterosexual men and women: cross-sectional and longitudinal data. Psychoneuroendocrinology 31, 715-723.

van Anders, S.M., Watson, N.V., 2006c. Social neuroendocrinology: effects of social contexts and behaviors on sex steroids in humans. Human Nature 17, 212-237.

Van Cauter, E., Blackman, J.D., Roland, D., Spire, J.P., Refetoff, S., Polonsky, K.S., 1991. Modulation of glucose regulation and insulin secretion by circadian rhythmicity and sleep. J. Clin. Invest. 88, 934-942.

Van Cauter, E., Leproult, R., Kupfer, D.J., 1996. Effects of gender and age on the levels and circadian rhythmicity of plasma cortisol. J. Clin. Endocrinol. Metab. 81, 2468-2473.

van der Meij, L, Buunk, A.P. van de Sande, J.P., Salvador, A., 2008. The presence of a woman increases testosterone in aggressive dominant men. Horm. Behav. 54, 640-644.

Vandenheede, M., Bouissou, M.F., 1993. Effect of androgen treatment on fear reactions in ewes. Horm. Behav. 27, 435-448.

Wabitsch, M., Hauner, H., Heinze, E., Bockmann, A., Benz, R., Mayer, H., Teller, W., 1995. Body fat distribution and steroid hormone concentrations in obese adolescent girls before and after weight reduction. J. Clin. Endocrinol. Metab. 80, 3469-3475.

Wingfield, J.C., Hegner, R.E., Dufty Jr., A.M., Ball, G.F., 1990. The “Challenge Hypothesis": theoretical implications for patterns of testosterone secretion, mating systems, and breeding strategies. Am. Nat. 136, 829-846.

Wirth, M.M., Welsh, K.M., Schultheiss, O.C., 2006. Salivary cortisol changes in humans after winning or losing a dominance contest depend on implicit power motivation. Horm. Behav. 49, 346-352.

Wood, R.I., 2004. Reinforcing aspects of androgens. Physiol. Behav. 83, 279-289. 